\title{
Something New in Cataloging
}

Miss Haskins is head cataloger at the Harvard College Library. This paper was read at the Conference of New England College Libraries at Wellesley College, June 10, 1944.

IN RECENT YEARS much emphasis has $I_{\text {been placed upon the cost of cataloging, }}$ with the result that catalog departments have become acutely aware of the problem and are always on the alert for new economies. How often an administrator will ask the question: How much does it cost you to catalog a book? or How many books can a cataloger do in a day? Margaret Mann, in discussing the subject, says: "This question of cost belongs ultimately to the chief librarian, but the economies should be the concern and responsibility of the head of the catalog department who should constantly study ways and means for simplifying routines and records without impairing the service." 1

In considering costs and economies in cataloging there are several factors which must be considered. The following are those which are especially significant at the present time at Harvard College and which are causing a reconsideration of methods of work.

First of all, there is the competition for the time and services of the cataloger. Material is constantly pouring into the library in the form of monographs, serials, and documents received by purchase, gift, or exchange-all of which has to be

1 Mann, Margaret. Introduction to Cataloging and the Classification of Books. 2d ed. (Library Curriculum Studies) Chicago, American Library Association, 1943, p. 249 . handled by the catalog department. Unless the work is carefully organized, the department may become a bottleneck through which the work passes in an unsystematic fashion. As the material comes in, decisions have to be made as to what is to be handled promptly, what classes are to receive precedence, and what may be postponed for some time.

Some types of work are regularly competing for first place. The order department cries to have the purchased books sent along rapidly because its files are clogging up; or someone has asked if a certain title is on order, only to find that the book was received some time ago but that there is no record of it in the catalog. Certain books come through to be cataloged in haste. These may have been ordered for an individual or for some course. In either case the cataloger drops whatever she is doing and sends the books through as rapidly as possible. But it is not the time of just one person which is thus interruptedit is the time of several all along the line through whose hands the books must pass. Similarly, the Library of Congress requests cooperative cataloging for a large number of the current titles received. In addition to taking at least the full time of one cataloger, this form of cataloging slows up the routine for these particular books because more detailed work is required for them.

Again, special requests for service come to the catalog department from various sources and vie with each other for priorities. The reference department has made contacts with an enthusiastic donor and 
asks that precedence be given to his gifts, in order to please him by getting them on the shelves promptly or in order that photographs may be taken of them for a newspaper article. Too much cannot be done to remain on the good side of this friend of the library and keep him interested. Or, a special collection is given to the library, and the request is made that it be cataloged by a certain date in the near future. The material may be of such a nature that there will be little or no call for it, but the catalog department must organize its work in order to put it through in the specified time.

There is also the instance in which a professor is placed in charge of a new special library and is anxious to put the collection into working order as soon as possible; or in which another special library is in need of reorganization. The responsibility for the work falls upon the catalog department.

In addition to all the above are the many little duties which are an accepted part of a cataloger's life but which prevent full time being given to putting books through. These consist of answering reference questions, searching for titles in process, conducting tours of the library for new staff members or guests, training new people, interviewing applicants, and so on.

\section{Space}

A second factor in considering costs and economies is the question of space. Dr. Osborn, in his paper on "The Crisis in Cataloging," says: "Far too little attention has been given in library literature to the organization of catalog departments, while in actual practice physical conditions have controlled matters to an undesirable extent." ${ }^{2}$ How many catalog departments have the space necessary for systematic handling of the material? At Harvard

2 Osborn, Andrew D. "The Crisis in Cataloging." Library Quarterly 11: 405, October 1941. there are now adequate accommodations for the staff and a liberal amount of working space, but difficulties still arise when a large quantity of material suddenly arrives. Shortage of space complicates the method of handling large collections of books and often necessitates shifting them several times before they are finally disposed of. In addition, crowded conditions have a bad effect on the morale of the cataloger.

\section{Methods of Work}

Methods of organizing the material are a third determining factor in considering the question of costs. In most libraries books are cataloged in a piecemeal fashion; that is, each book is considered individually, as it comes up, from the author and title approach and often from the subject approach. There is little system possible in this method of working. Those books which cannot be handled in a day are set aside until finally a large accumulation results. Then the question arises as to the best way of working this off. Some libraries attempt to tackle it on a chronological basis by cataloging the books in the order of receipt, but this still means working by the piecemeal method.

\section{Organization of Work}

The last factor is the plan, common in catalog departments, of organizing from the subject point of view. This has much in its favor, but, according to the experience of several large libraries which have attempted to work out cost figures, it is the descriptive cataloging which is the more costly. Therefore, does it seem logical to plan the organization on a basis that favors the less expensive side of the work, namely, subject cataloging?

In March 1942 the Harvard catalog department moved into new quarters made possible by the building of the Houghton Library for the housing of the rare books. 
Up to that time the department was organized by subject. There were many advantages in this organization, but it was very difficult to control the flow of work. One person would be swamped with work while another would be looking around for something to do, all depending upon the subjects with which each was working. Taking advantage of the shift and of more space, the department was reorganized on the basis of two groups-the one to handle material that can move along rapidly, such as titles for which Library of Congress cards are available, nonfiction which presents no difficulties, fiction, other editions, second copies, and books which may be sent directly to the New England Deposit Library; the other group to handle the more difficult material involving research problems, out-of-the-way languages, and so on. This second group is organized on the traditional subject and language basis. In such an organization the flow of work can be better controlled-the difficult books do not slow up the work on the easier books and the quantity of easy books does not prevent working on those requiring research.

\section{Cataloging Drives}

However, during the last two years, material poured in at such a rate that it was impossible to keep up with it, and finally all available space for storing it was filled. Most of it was acquired by the library through large-lot purchases. With the realization that this accumulation must be worked off before the end of the war, when there would be an influx of material from Europe, the first cataloging drive was organized in March 1943. A period of "total cataloging" was declared for nine weeks. All members of the department who could possibly be spared were drafted for either full or part time. This meant that the efforts of the entire department were concentrated on cataloging alone and that the variety of noncataloging duties which occupy so much of a cataloger's time were eliminated or suspended as far as possible. Four full-time people were delegated to handle the newly-purchased books and the cooperative cataloging.

The total number of professional people taking part in the drive proper totaled eighteen. They were divided into several groups for literature, nonliterature, and deposit library books. Serials, documents, and pamphlets were not treated. There was no arrangement of the titles within the groups; the cataloging was on the piecemeal basis. In this period of nine weeks, 19,858 titles and 22,183 volumes were put through. This represents an average of 367 titles cataloged per day or 25 titles per cataloger per day. ${ }^{3}$

Júst a year later working space was again filled to overflowing and the stacks were being used to store the thousands of books which had been acquired by the library. Another drive was inevitable. From experience gained in the first, it was realized that better preliminary arrangement of the material was necessary. This would result in less duplication and more systematic cataloging. Therefore, it was decided to arrange all the books alphabetically before starting to catalog them. Since there was not room enough to alphabetize all the books at once, the drive was divided into two parts: the first, on books for the deposit library only; the second, on books for the stacks. In April 1944 all available catalogers (seventeen, of whom nine were full time) were again drafted, but only for a two weeks' period. This time just two groups were formed, one for literature and the other for nonliterature. No current work was done during this period,

3 A few words of explanation should be made concerning cataloging as it is done at Harvard. This term covers only the actual descriptive and subject cataloging. All clerical processes, such as preliminary searching, typing, shelflisting, filing, etc., are quite separate and distinct from the work of the catalogers. 
with the exception of haste books and cooperative cataloging. For each group the books were arranged alphabetically, with the result that many titles by a single author could be cataloged at one time. The final figures for this drive were $\mathrm{I} 3,00 \mathrm{I}$ titles and 13,729 volumes. When broken down, these figures show that for this class of material a daily average of 1,083 titles was achieved, or 83 titles per cataloger per day. The books were sent along daily, by the hundreds, for the end processes of classification, stamping, and tagging. It was an impressive sight to see them come pouring in and at the same time to watch them being packed into boxes and shipped right out to the deposit library.

The fact that so many volumes were handled in two weeks is due in large part to the simplified cataloging which is used for the deposit library books. Since there is expected to be little call for the books sent to the deposit library, detailed description is not considered necessary and, therefore, a simplified method of cataloging them has been worked out. The principal difference is the omission of the entire collation with the exception of the volume statement. This single factor saves an immense amount of time. The transcription of the title is the same as for books in the stacks, but little or no time is given to establishing full names of authors, dates of publication, and so on. A minimum of research is spent on determining the authorship of anonymous books and on other bibliographical points. Only those notes are given which are essential in identifying a book in ordinary searching. There is no classification by subject; the books are arranged by size and are assigned running numbers within designated size groups.

Having thus disposed of thirteen thousand volumes, enough space was now available to arrange the rest of the books which were to be cataloged for the stacks. In
June a third drive was held, over a period of two and one half weeks, but this time was interrupted by a holiday and irregular hours. The same organization was followed as for the previous drive, but since these books were for the stacks, more detailed cataloging was required and subject classification was necessary. During the drive descriptive cataloging and subject heading were done for all titles and classification for those titles to which notations could readily be assigned. The only titles which were completely put through, that is, shelflisted and sent to the stacks, were those falling in English and American literature. The rest were arranged by broad classes and were actually classified as soon as possible after the drive. In this way 7,848 titles and 8,342 volumes were cataloged, or 504 titles per day, each cataloger averaging 55 per day.

\section{New Ideas on Organization of Work}

The amount of work accomplished by means of these drives has led to the development of new methods of organizing the current work. Broadly speaking, the material coming into the library seems to fall into three classes, each of which can be treated in a particular way. As Dr. Madan, a former librarian of the Bodleian, has said: "We have learnt not to regard books in a library as all equal in appearance and all to be treated alike, as if they were a rank of drilled soldiers. The lesser books must stand back, and the greater be brought into prominence."

The first class consists of those purchased and gift books which should be put through as promptly as possible. These have to be handled on the piecemeal basis, because they cannot be allowed to accumulate. From figures kept two years ago it

4 As quoted in Sharp, Henry Alexander. Cataloguing; a Textbook for Use in Libraries. $2 \mathrm{~d}$ ed., rev. and enl. London, Grafton \& Co., 1937, p. 163 . 
is estimated that a cataloger at Harvard averages about sixteen books a day for this type of material. This is an expensive method, but for this class it is unavoidable. Economies in cataloging these books will have to be worked out along the lines of simplification of records and routines rather than in the basic method of organization. Cooperative cataloging naturally falls here, but the same figures do not apply since more detailed work is required by the $\mathrm{Li}$ brary of Congress.

Gifts and purchases for which there is no pressure make up the second group of material currently coming into the library. If carefully selected, there is no reason why this class of books should not be allowed to accumulate for a short time. The period would naturally be determined by local conditions. At Harvard space is the chief factor which has to be considered. Since it is known, from experience on the drives, approximately how many books can be put through in a week, the plan suggests itself to allow the books to accumulate until that number is reached. A week's drive can then be organized to send the material along. During this period the books should be arranged alphabetically, in order that any title may be easily located upon request. They are then ready for systematic and economical handling when the time comes. It was this kind of material which was cataloged in the last drive.

The books which are kept for historical or bibliographical interest, but for which we expect there will be little call, make up the third and last type. To this class belong the books which Harvard sends to the deposit library. They are selected chiefly from incoming gifts and large-lot purchases, although occasionally an individually bought book may be included. There is no harm in accumulating such material indefinitely, but here again the length of the period is necessarily determined by the space which is available. Eventually these books also should be arranged alphabetically before they are worked on, but there is little likelihood of having to search for a particular title during the period of accumulation.

\section{Interpretation of the Figures}

Before summarizing the results of the cataloging done at Harvard on the three classes of material, several words of caution must be used. As with virtually all library statistics, the figures have no value apart from the set of local circumstances that applied at the time the work was done. To interpret the Harvard data a variety of factors must be considered: the quality and experience of the catalogers involved, the benefits that come from the system of preliminary cataloging, ${ }^{5}$ the amount of time spent on establishing names and dates, etc. Moreover, it is not to be expected that the same figures would necessarily hold in future work of this kind at Harvard. What can be said is that approximately 50 per cent more work can be done on books handled on a piecemeal basis if conditions of "total cataloging" exist; approximately three times as many books as normally can be cataloged under similar conditions if the books are arranged alphabetically for the benefit of the descriptive cataloger; and approximately five times as many Class III books can be cataloged as other books. In addition it must be stated that these averages hold only for concentrated work during a short period and could not be maintained over any extended length of time.

Class I material (consisting of books to be cataloged promptly) is handled piecemeal, and for this class it is estimated that a Harvard cataloger can average 16 titles

This system is described in Currier, Thomas Franklin. "Preliminary Cataloging." College and Research Libraries 1 : $235-40$, June 1940 . 
per day. In the first drive the books were cataloged on the same basis by the equivalent of fourteen and one-half full-time catalogers. Each averaged 25 titles a day, making a daily total average for the group of 367 .

Class II (consisting of gifts and purchases for which there is no pressure) was cataloged in the third drive by the equivalent of eleven full-time catalogers, each averaging 55 titles a day, with a daily total of 504 .

Class III (consisting of books for the deposit library) was cataloged in the second drive by thirteen full-time catalogers, with a daily average of 83 titles apiece and a total of $\mathrm{I}, 083$. For this class simplified cataloging is used.

Therefore, if asked how many books a cataloger can do in a day, the following answer might be given: for Class I, normally sixteen, and on a drive, twenty-five; for Class II, fifty-five; and for Class III, eighty-three. It is also interesting to note that in one month the descriptive and subject cataloging was done for half as many titles as the total production for the year.

For the sake of emphasis, let it be repeated here that these figures have value only for crystallizing thinking about various cataloging procedures. They have no intrinsic value; they have no value for any other library. In other words, they are not norms.

\section{Conclusions}

There are certain conclusions which have been drawn, based on experience from these cataloging drives.

I. If the work is organized into the three classes just mentioned, adequate working space must be provided. It takes plenty of room (just as it needs an adequate staff) to arrange thousands of books alphabetically, but the resulting economy when they are finally put through should warrant the provision of both.
2. On the basis of such an organization, the number of factors competing for the cataloger's time will be reduced and the sense of pressure will be greatly lessened. Other departments in the library will be notified that the catalog department is organizing its work in this way, so there should then be no misunderstanding or criticism when the material is allowed to accumulate. The department will always be ready to change a book from one class to another if the treatment of a certain title is questioned.

3. An alphabetical arrangement of an accumulation of books results in economical and systematic cataloging. If the material comes in, in large lots, it will be advantageous to alphabetize the books before they are searched. Ordinarily, however, they will be arranged as they are added to the accumulation. In the end a second rapid sorting may weed out duplicates and allow a redistribution of some of the titles.

When they are put through, it takes much less time to catalog six books by one author at one time than to handle the titles separately six different times. In this connection also, the new Library of Congress printed catalog provides a distinct advantage. During the drives the catalogers were able to take the volumes to their desks and make the greatest use of the bibliographical information contained there. The books of a number of authors could be worked on from just one volume of the printed catalog.

4. The drives should be organized for short periods of time and held more frequently. This was very apparent from the figures of the first drive, which continued for nine weeks. The maximum production was reached in the sixth week, after which there was a decided slump, showing that the staff was tired.

5. As a mark of appreciation and for the welfare of the staff, it would seem proper to grant some time off after such concentrated work.

The major interest in these drives and in the ideas for organization that have resulted from them is not only the saving in cost, which would naturally follow a more systematic treatment of the work, but also the opportunity which may be afforded for

(Continued on page 32I) 
functionary was supposed to cure many of the librarian's headaches while occupying, from the library school's point of view, an especially attractive post-a post in which to place promising young men who, understandably, wanted to become librarians by short-cutting the generally accepted methods. In some cases this worked out, and is still working out, in a manner satisfactory to all concerned, but the idea has never progressed beyond the trend stage. It is possible that the number of actual appointments of readers' division chiefs may remain a mere trend and never reach the proportions of a movement.

However, the two positions are not analogous because of the potential markets. The most casual consideration of the placement possibilities for the post of assistant to the librarian shows the demand circumscribed by the number of very large libraries-the only ones that can afford to carry the extra cost of a relatively highsalaried staff member whose duties will be, at best, policy interpretation of a high degree. But in the case of the readers' division chief, the potential market may be said to include every college and university library where it is recognized that a close relationship between the faculty and staff is desirable and is worth paying for and where it is also recognized that the librarian himself cannot find time to act as a complete liaison officer.

Small libraries should and will depend upon the librarian and the department heads. Some of the larger libraries will want to employ a sort of supercirculation chief or superreference chief. In such cases the supercirculation or superreference chief will, in many instances, be a readers' services chief with merely another title. Except as one of the already heavily stressed accouterments for entree, the actual title of assistant librarian in charge of readers' services is not advocated here because of any inherent magical quality in the combination of words.

Other and better solutions will undoubtedly present themselves or be discovered later for a proper medium of readers' service coordination and library-faculty cooperation, but for the time being, in college and university libraries, the authors suggest unification of readers' service under a readers' division chief.

\section{Something New in Cataloging}

\section{(Continued from page 296)}

doing the many things a catalog department always wants to do but for which it never has the time.

If several drives of a week's duration are planned, the bulk of the work for the year will be compressed into about two months. This should mean that during the remainder of the year the cataloger will not be under pressure and will be free to work on a number of matters which normally have to be set to one side waiting for a better day which never seems to come. This will provide a variety and interest in the cataloger's program which is now often lacking. 